\title{
Facile Synthesis of Ni-Co LDH Nanocages with Improved Electrocatalytic Activity for Water Oxidation Reaction
}

\author{
Changshui Wang, Jiahui Zhang, Caiyan Shi, Dandan Cai ${ }^{*}$ \\ State Key Laboratory for Chemistry and Molecular Engineering of Medicinal Resources, Ministry of \\ Science and Technology of China; School of Chemistry and Pharmaceutical Sciences, Guangxi \\ Normal University, Guilin, 541004, P. R. China. \\ *E-mail: caidandan86@163.com,
}

doi: $10.20964 / 2017.11 .27$

Received: 7 August 2017 / Accepted: 3 September 2017 / Published: 12 October 2017

\begin{abstract}
The development of an inexpensive, efficient and robust water oxidation catalyst is important to achieve water splitting for renewable energy production. Herein, nickel-cobalt layered double hydroxides (Ni-Co LDHs) were rationally synthesized by a facile method and can be served as efficient electrocatalysts for water oxidation. For comparison, Ni-Co LDH nanoflowers have also been synthesized by controlling the synthetic process. The composition and morphologies of the catalysts were characterized by X-ray diffraction (XRD), field-emission scanning electron microscopy (FESEM) and X-ray photoelectron spectroscopy (XPS). The as-obtained Ni-Co LDH nanocages exhibit a high catalytic activity toward the water oxidation reaction (WOR). The electrochemical results show that the overpotential of Ni-Co $\mathrm{LDH}$ nanocages electrode was $350 \mathrm{mV}$ at a catalytic current density of $10.0 \mathrm{~mA} \mathrm{~cm}^{-2}$ in $1.0 \mathrm{M} \mathrm{KOH}$. Moreover, the Tafel slope was as low as $\sim 93 \mathrm{mV} \mathrm{dec}^{-}$ 1 . The unusual catalytic properties of Ni-Co LDH nanocages could be attributed to the hollow structure and the synergetic effect between Ni metal and Co metal.
\end{abstract}

Keywords: Ni-Co LDH; nanocages; ZIF-67; electrocatalysis; water oxidation

\section{$\underline{\text { FULL TEXT }}$}

(C) 2017 The Authors. Published by ESG (www.electrochemsci.org). This article is an open access article distributed under the terms and conditions of the Creative Commons Attribution license (http://creativecommons.org/licenses/by/4.0/). 